\title{
Purification and characterization of four extracellular $1,3-\beta$-glucanases of Botrytis cinerea
}

\author{
K.-Peter Stahmann, ${ }^{*}$ Karl-Ludwig Schimz and Hermann Sahm \\ Institut für Biotechnologie 1, Forschungszentrum Jülich GmbH Postfach 1913, D-5170 Jülich, Germany
}

(Received 22 March 1993; revised 28 June 1993; accepted 1 July 1993)

\begin{abstract}
The filamentous fungus Botrytis cinerea was found to produce four 1,3- $\beta$-glucanases (Glu I, II, III, IV). These enzymes were visualized by activity-staining after separation by native polyacrylamide gel electrophoresis (PAGE). During growth on glucose as the single carbon source, only Glu III was detectable in the culture supernatant of $B$. cinerea. After glucose was exhausted from the medium, the extracellular $(1,3)(1,6)-\beta$-D-glucan (cinerean) capsule of the fungus was degraded. In this phase the other three enzymes became detectable and the amount of all four enzymes increased. The enzyme with the greatest activity was Glu II, which was purified to homogeneity by SDS-PAGE. Its $M_{\mathrm{r}}$ was 75000 and its isoelectric point (pI) was 5.2. Glycosylation of Glu II was shown by the periodic acid/Schiff reaction after SDS-PAGE. Glu II cleaved cinerean and laminarin. Both substrates were degraded in an exo-manner as shown by product characterization, and by studying the viscosity decrease in comparison with the liberation of reducing groups. The concentration of substrate that gave halfmaximal velocity $\left(S_{0.5}\right)$ for Glu II was $580 \mu \mathrm{g} \mathrm{ml}^{-1}$ for cinerean and $152 \mu \mathrm{g} \mathrm{ml}^{-1}$ for laminarin. For Glu III, also purified to homogeneity by SDS-PAGE, an $M_{\mathrm{r}}$ of 84000 and a pI of 3.6 were determined. Glu III cleaved laminarin $\left(S_{0.5} 119 \mu \mathrm{g} \mathrm{ml}^{-1}\right)$ but not cinerean. Glu I and Glu IV were purified by activity-stained native PAGE. Both enzymes cleaved cinerean and laminarin in an exo-manner. Glu I focused at pI 4.9; its $S_{0.5}$ was $275 \mu \mathrm{gl}^{-1}$ with cinerean and $138 \mu \mathrm{g} \mathrm{ml}^{-1}$ with laminarin. The $\mathrm{pI}$ of Glu IV was 3.4 ; its $S_{0.5}$ was $171 \mu \mathrm{g} \mathrm{ml}^{-1}$ for cinerean and $27 \mu \mathrm{g} \mathrm{ml}^{-1}$ for laminarin.
\end{abstract}

\section{Introduction}

Many fungal 1,3- $\beta$-glucanases have been the subject of basic or applied research. Their nutritional function is evident by the extracellular degradation of $1,3-\beta$-glucans serving as carbon sources (Bamforth, 1980; Stahmann et al., 1992). Parasitic fungi may use them for degradation of the host cell wall (Jones et al., 1973; Bodenmann et al., 1984). Their involvement in fungal cell wall formation during hyphal tip growth, as tightly balanced antagonists of glucan synthase, is controversial (Bartnicki-Garcia, 1968, 1987; Wessels, 1988). 1,3- $\beta$-Glucanases have been studied in order to use them for various technical purposes such as preparing protoplasts (Kitamoto et al., 1987), analysing fungal cell wall structure (Usui et al., 1985), clarifying slimy must (Dubourdieu et al., 1985),

\footnotetext{
* Author for correspondence. Tel. +492461 612843; fax +49 2461 612710 .
}

Abbreviations: HPTLC, high-performance thin-layer chromatography; $\mathrm{S}_{0.5}$, substrate concentration at half-maximal velocity; TEMED, $N, N, N^{\prime}, N^{\prime}$-tetramethylethylenediamine. and in the determination or degradation of barley $\beta$ glucan, which causes problems if it accumulates during the brewing process (Bamforth, 1980). In most cases, a system of $1,3-\beta$-glucanases rather than a single enzyme was found. In the yeasts Saccharomyces cerevisiae and Kluyveromyces phaseolosporus, seven and four different 1,3- $\beta$-glucanases respectively, have been described (Nombela et al., 1988). They are distinguishable by substrate specificity, mode of action, $K_{\mathrm{m}}, M_{\mathrm{r}}$, isoelectric point (pI), localization in the culture, and conditions of formation. Penicillium oxalicum was found to form four enzymes during the so-called autolytic phase (CopaPatino et al., 1989). In Penicillium italicum (Sancez et al., 1982) three developmentally-regulated $1,3-\beta$-glucanases were identified. Sclerotinia sclerotiorum (Jones et al., 1973) and Sclerotium glucanicum (Rapp, 1989) produce endo- and exo-1,3- $\beta$-glucanases. In Trichoderma longibrachiatum (Tangerone et al., 1989) and Trichoderma harzianum (Kitamoto et al., 1987) only a single 1,3- $\beta$ glucanase was detected.

The filamentous fungus Botrytis cinerea Pers.: Fr., anamorph of the ascomycete Botryotinia fuckeliana (Lib.) Whetzel, produces an extracellular $(1,3)(1,6)-\beta$-D- 
glucan (Montant \& Thomas, 1977, 1978) termed cinerean (Dubourdieu et al., 1985). This polysaccharide is produced during growth and forms a capsule adhering to the hyphae. In a recent paper (Stahmann et al., 1992) it was shown that cinerean can be degraded by the fungus and can be used as the sole source of carbon and energy. This study also indicated that $B$. cinerea forms at least two 1,3- $\beta$-glucanases. The culture supernatant harvested during the cinerean formation phase degraded laminarin but not cinerean. This result is in agreement with the work of Dubourdieu \& Ribereau-Gayon (1980), who described a laminarin-degrading activity which could not cleave cinerean. Urbanek \& Zalewska-Sobczak (1986) studied apple-rot caused by $B$. cinerea. They found two 1,3- $\beta$-glucanases, one attacking laminarin in an exomanner and the other in an endo-manner, but they did not examine the cleavage of cinerean.

The objective of this study was to isolate and characterize the cinerean-degrading enzyme. A further aim was to determine how many $1,3-\beta$-glucanases are formed by $B$. cinerea and to see whether there is any influence of culture conditions or growth phase on the enzyme pattern. Are there different enzymes which can be distinguished by substrate specificity, affinity, and mode of cleavage, or is the heterogeneity a result of glycosylation or partial proteolytic digestion?

\section{Methods}

Chemicals. Laminarin (1,3- $\beta$-glucan) was purchased from Sigma. Carboxymethylcellulose was supplied by Serva. Pustulan was obtained from Calbiochem and $p$-nitrophenyl $\beta$-D-glucopyranoside from Merck. Cinerean was prepared from submerged cultures of $B$. cinerea as described previously (Stahmann et al., 1992). All other reagents were analytical grade from commercial sources.

Organisms and growth conditions. Botrytis cinerea Pers.: Fr. strain Lu $1458 \mathrm{MaB}$ (Stahmann et al., 1992) and single-ascospore isolates of Botryotinia fuckeliana SAS 405 and SAS 56 (Faretra et al., 1988) were used. The strains were cultured on solid complex medium for maintenance, and in liquid mineral salts medium for cinereanase formation, as described previously (Stahmann et al., 1992).

Enzyme assays. Cinerean- or laminarin-degrading enzymes were assayed in reaction mixtures comprising $0.4 \mathrm{ml}$ substrate $(0.2 \%$ of the specific polysaccharide in $50 \mathrm{~mm}$-sodium acetate buffer, $\mathrm{pH} 5.0$ ) and $0.1 \mathrm{ml}$ enzyme solution. The mixtures were incubated at $37^{\circ} \mathrm{C}$ for $1 \mathrm{~h}$ and the reactions stopped by boiling the mixture briefly. Reducing sugars were determined by the Nelson-Somogyi method (Nelson, 1944; Somogyi, 1952). One unit was defined as the amount of enzyme liberating $1 \mu \mathrm{mol}$ of reducing equivalent (glucose was used for calibration) per min under the assay conditions. Various buffers from $\mathrm{pH} 2.0$ to $\mathrm{pH} \mathrm{9.0} \mathrm{were} \mathrm{used} \mathrm{to} \mathrm{study} \mathrm{the} \mathrm{effect} \mathrm{of} \mathrm{pH}$ on the enzyme activity: $40 \mathrm{mM}$-citrate/ $\mathrm{HCl}(\mathrm{pH} 2 \cdot 0-4.0)$; citrate/hydrogen phosphate (pH 3.5-6.5); phosphate ( $\mathrm{pH} 6 \cdot 0-7.5) ; \quad$ Tris/HCl (pH 7.5-9.0). Temperature-dependent stability was investigated by incubating the enzyme solution at different temperatures in $50 \mathrm{~mm}$-sodium acetate buffer (pH 5.0) followed by a standard assay. The sugars released were analysed on high-performance thin-layer chromatography (HPTLC) Silica Gel 60 plates (Merck) as described previously (Pielken et al.,
1990). Additionally, sugars were separated and quantified, as their borate complexes, by anion-exchange chromatography (Carbohydrate Analyzer LC 2000; Biotronik) and detected with $\mathrm{Cu}^{2+} /$ bicinchoninate reagent as described by Schimz et al. (1985).

A second enzyme test system was based on viscometry. Four millilitres of $0.6 \%$ cinerean in $0.05 \mathrm{M}$-sodium acetate buffer (pH 5.0) was mixed with $40 \mu \mathrm{l}$ enzyme solution and incubated at $37^{\circ} \mathrm{C}$. To stop the reaction, the assay mixture was briefly boiled. Flow curves of this mixture containing the partially degraded polysaccharide were obtained using a Rotovisco CV 100 (sensor system Me 30; Haake). Measurements were taken at $25^{\circ} \mathrm{C}$ with a linearly increasing rate of shear $\left(0-300 \mathrm{~s}^{-1}\right.$ within $\left.8 \mathrm{~min}\right)$. The samples were presheared and, after a break of $120 \mathrm{~s}$, were measured again twice to examine their reproducibility.

Each determination of enzyme activity was corrected by subtracting the absorbance or viscosity change determined in an identical assay with heat-denatured enzyme. All determinations were carried out twice, and mean values were calculated. For kinetic studies, the means and standard errors of three determinations were computed.

Isoelectric focusing. The method used was similar to that described by Robertson et al. (1987). Gels were poured $1.5 \mathrm{~mm}$ thick from the following mixture: $8.2 \mathrm{ml}$ distilled water; $2 \mathrm{ml}$ acrylamide mixture (30\%, w/v, acrylamide; $0.8 \%, \mathrm{w} / \mathrm{v}$, bisacrylamide); $0.4 \mathrm{ml}$ ampholyte $\mathrm{pH}$ range $2.5-5.0 ; 0.2 \mathrm{ml}$ ampholyte $\mathrm{pH}$ range $5-8 ; 1.2 \mathrm{ml}$ glycerol; $19 \mu \mathrm{l} N, N, N^{\prime}, N^{\prime}$-tetramethylethylenediamine (TEMED); $48 \mu \mathrm{l} 10 \%$ $(\mathrm{w} / \mathrm{v})$ ammonium persulphate. The cathode solution was $25 \mathrm{~mm}-$ $\mathrm{NaOH}$ and the anode solution $20 \mathrm{~mm}$-acetic acid. Samples and protein standards were mixed with an equal volume of $60 \%(\mathrm{v} / \mathrm{v})$ glycerol and $4 \%(\mathrm{v} / \mathrm{v})$ ampholyte of the same range used to prepare the gel. Electrophoresis was performed at $10^{\circ} \mathrm{C}$ in a cooled vertical minigel system (SE 200, Hoefer) for $1.5 \mathrm{~h}$ at $200 \mathrm{~V}$ constant voltage, followed by $1.5 \mathrm{~h}$ at $400 \mathrm{~V}$ constant voltage.

Native polyacrylamide gel electrophoresis (PAGE). This technique was carried out according to Pan et al. (1989). Polyacrylamide resolving gels $(17.5 \%, 1.5 \mathrm{~mm})$ were prepared by mixing $9.4 \mathrm{ml}$ acrylamide mixture, $3.0 \mathrm{ml} 2 \mathrm{M}-\mathrm{Tris} / \mathrm{HCl}(\mathrm{pH} 8.8), 3.5 \mathrm{ml}$ distilled water, $8 \mu \mathrm{l}$ TEMED and $120 \mu \mathrm{l} 10 \%(\mathrm{w} / \mathrm{v})$ ammonium persulphate. The stacking gel included $0.75 \mathrm{ml}$ acrylamide mixture, $1.5 \mathrm{ml}$ Tris $/ \mathrm{HCl}$ (pH 6.8), $3.6 \mathrm{ml}$ distilled water, $4.4 \mathrm{ml}$ TEMED and $45 \mu \mathrm{l} 10 \%(\mathrm{w} / \mathrm{v})$ ammonium persulphate. A $20 \mathrm{mM}$-Tris solution, adjusted with glycine to $\mathrm{pH} 8 \cdot 3$, was used as the anode and cathode buffer. The gel was run for $12 \mathrm{~h}$ in the cooled vertical minigel system at $0{ }^{\circ} \mathrm{C}$ and $5 \mathrm{~mA}$ constant current.

Denaturing PAGE. Discontinuous SDS-PAGE was run in a vertical gel chamber SE 400 (Hoefer), applying the method of Laemmli (1970) using a $12.5 \%$ polyacrylamide gel.

Staining of polyacrylamide gels. 1,3- $\beta$-Glucanase staining was performed in a similar way to Pan et al. (1989). After electrophoresis the gel was washed three times with distilled water. Following equilibration in $0.5 \mathrm{M}$-sodium acetate ( $\mathrm{pH} 4.5)$ it was incubated in the same buffer, containing $6.7 \mathrm{mg}$ laminarin $\mathrm{ml}^{-1}$, for $2 \mathrm{~h}$ at $37^{\circ} \mathrm{C}$. After washing the gel three times with distilled water it was heated in a boiling water bath with $1 \mathrm{M}-\mathrm{NaOH}$, containing $1.5 \mathrm{~g}$ 2,3,5-triphenyltetrazolium chloride $1^{-1}$, until red bands appeared. The intensity of these bands was approximately proportional to the applied activity and incubation time with laminarin. The stained gels were quickly transferred to $7 \cdot 5 \%$ acetic acid to reduce background staining and to conserve the contrast.

Proteins were visualized by silver staining (Meril et al., 1981) to prove homogeneity in SDS and native PAGE, and by rapid Coomassie Brilliant Blue R-250 staining (Robertson et al., 1987) to identify the standards in isoelectric focusing gels.

Glycoprotein visualization was based on the periodic acid/Schiff stain developed by Zacharius et al. (1969). 
Purification procedure. The enzymes were purified from the culture broth of $B$. cinerea after cultivation for $15 \mathrm{~d}$ in mineral salts medium with glucose as the sole carbon source. The cell-free culture liquid was concentrated 100 -fold by lyophilization and applied to a gel filtration column (Sephacryl 200 superfine, Pharmacia) equilibrated with $50 \mathrm{~mm}-$ Tris/ $\mathrm{HCl}(\mathrm{pH} \mathrm{7.0)}$ containing $0.5 \mathrm{M}-\mathrm{NaCl}$. Active fractions were combined, concentrated by ultrafiltration (Ultrafree $30 \mathrm{kDa}$, Millipore) and dialysed against $5 \mathrm{~mm}$-succinate $/ \mathrm{NaOH}$ buffer $(\mathrm{pH} 4 \cdot 0$ ). This solution was applied to a carboxymethylcellulose Biogel (CM-Biogel) (Bio-Rad) column equilibrated with the same buffer. The binding glucanases were eluted by a linear gradient of $0-300 \mathrm{~mm}-\mathrm{NaCl}$ after washing the column with three volumes. The glucanases which did not bind were applied to a DEAE-Sephadex A-25 (Pharmacia) column after concentration and dialysis against the column buffer $(50 \mathrm{mM}$ Tris/ $\mathrm{HCl}, \mathrm{pH} 7 \cdot 0$ ). Elution was achieved by a linear gradient of $0-250 \mathrm{~mm}-\mathrm{NaCl}$. The pooled fractions of DEAE-Sephadex and carboxymethylcellulose Biogel containing glucanase activity were concentrated separately and then applied to a Sephadex G-100 column (Pharmacia), run with $200 \mathrm{~mm}$-Tris/ $\mathrm{HCl} \mathrm{pH} 8.0$ containing $0.1 \mathrm{M}$ $\mathrm{NaCl}$. During column chromatography, protein was located by absorbance at $280 \mathrm{~nm}$. The Markwell method (Markwell et al., 1978) was used to estimate protein concentration of the samples, with bovine serum albumin as the standard.

\section{Results}

\section{Conditions for 1,3- $\beta$-glucanase formation}

Analysis of $B$. cinerea submerged culture supernatants by native PAGE and activity-staining with laminarin as the substrate showed that up to four 1,3- $\beta$-glucanases, termed Glu I, II, III and IV, were formed (Fig. 1).

As recently reported (Stahmann et al., 1992), the formation of $\beta$-glucanases with cinerean-degrading activity (cinereanase) is regulated by the carbon source.

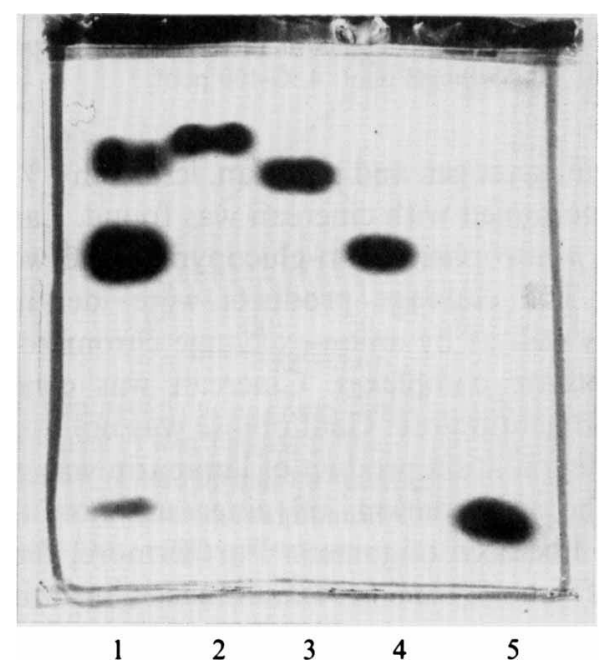

Fig. 1. Heterogeneity of 1,3- $\beta$-glucanase. $B$. cinerea submerged culture supernatants were analysed by native PAGE $(17.5 \%$ gel); after incubation with laminarin, activity-staining was carried out. Lanes: 1, culture supernatant containing Glu I, II, III, IV; 2, purified Glu I; 3, purified Glu II; 4, purified Glu III; 5, culture supernatant containing Glu IV.
When $B$. cinerea is cultivated in mineral salts medium with glucose as the sole carbon source, cinerean is formed during the growth phase and cinereanase activity is not detectable. In contrast, laminarinase activity is present during this growth phase. When glucose is exhausted from the medium, cinereanase activity becomes measurable and both laminarinase and cinereanase activity increase.

During the growth phase on glucose, only Glu III was detectable by native PAGE. When cinerean was degraded after glucose consumption, Glu I, II and IV were additionally found. The concentration of all four enzymes increased during the course of the cinerean degradation phase. These culture conditions led to the same zymogram in B. cinerea Lu $1458 \mathrm{MaB}$, SAS 56 and SAS 405 cultures. Samples compared in adjacent lanes on a gel showed the same 1,3- $\beta$-glucanase pattern. When $B$. cinerea $\mathrm{Lu} 1458 \mathrm{MaB}$ was cultured with cinerean or laminarin as the sole carbon source, only Glu I and Glu IV were found in the culture supernatant. When gentiobiose was used as the sole carbon source, only Glu IV was detectable. After growth with glycerol as the carbon source, no 1,3- $\beta$-glucanase formation was detectable in a culture supernatant concentrated 100 -fold. It is concluded that the formation of each enzyme is regulated separately. The detection of Glu III during growth on glucose while cinereanase activity was not detectable (Stahmann et al., 1992) indicated that Glu III cleaved laminarin but not cinerean.

\section{Isoelectric points and carboxymethylcellulose-binding properties}

A useful property for the distinction and separation of proteins is the pI. The 1,3- $\beta$-glucanases of $B$. cinerea focused at pH 4.9 (Glu I), pH 5.2 (Glu II), pH 3.6 (Glu III) and pH 3.4 (Glu IV) (Fig. 2). They were divided into two groups. At pH 4.0 Glu I and Glu II were positively charged while Glu III and Glu IV were negatively charged. These results were confirmed and used in a separation step with carboxymethylcellulose. While Glu I and Glu II bound to the ion exchanger, Glu III and Glu IV were eluted at about one column volume (Fig. 3).

\section{Purification and properties of Glu II}

To study the properties of the main cinereanase produced during the cinerean-degrading phase after glucose consumption, a purification procedure as described in Methods was carried out (Table 1). The cinereanase isolated in this way was homogeneous in native PAGE and was identified as Glu II (Fig. 4). The protein was also homogeneous in SDS-PAGE and had an $M_{\mathrm{r}}$ of 75000 (Fig. 5). Periodic oxidation and stainirg with fuchsin 

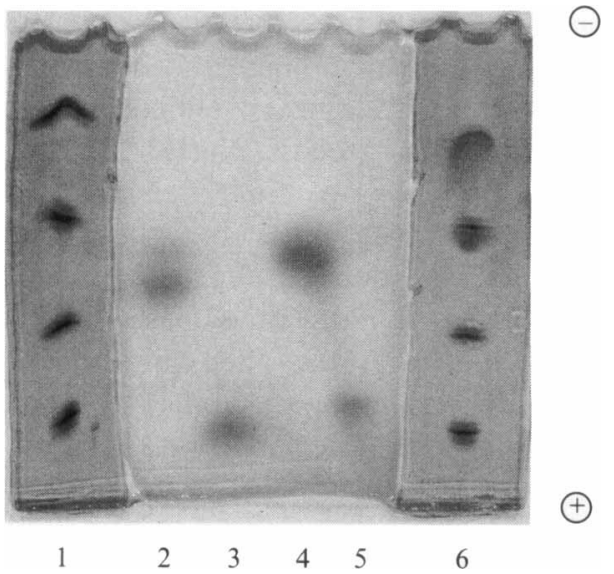

Fig. 2. Determination of the isoelectric points of Glu I, Glu II, Glu III and Glu IV. The following samples were applied to a native polyacrylamide gel. Lanes: 1 and 6, amyloglucosidase (pI 3.6), trypsininhibitor (pI 4.6), carbonic anhydrase (pI 5.4), carbonic anhydrase (pI 6.6); 2, Glu I; 3, Glu IV; 4, Glu II ; 5, Glu III. After focusing, lanes 1 and 6 were stained with Coomassie Blue; lanes $2-5$ were activitystained after incubation with laminarin. The isoelectric points of the glucanases were calculated after linear regression of $R_{F}$ and $\mathrm{pI}_{\text {standard }}$.

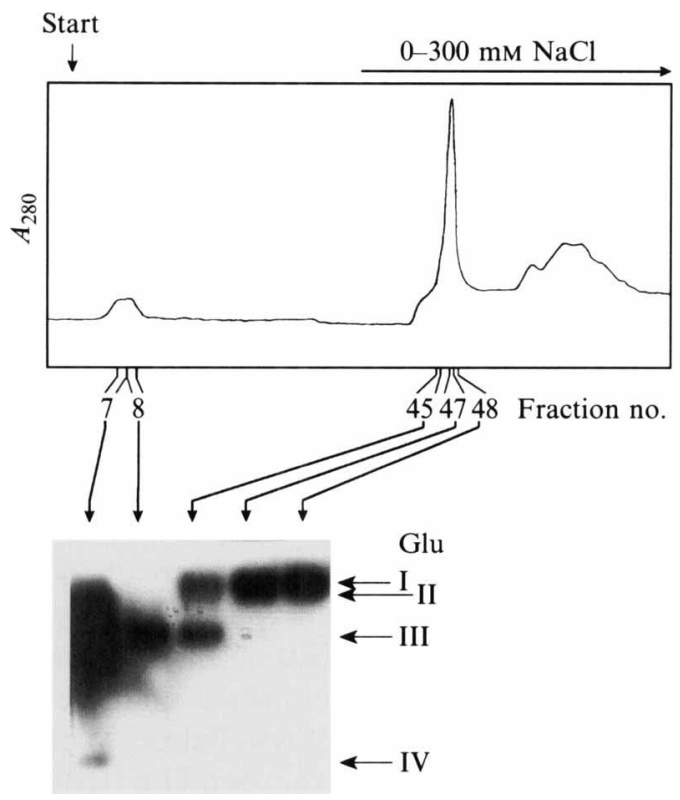

Fig. 3. Carboxymethylcellulose-binding properties of $1,3-\beta$-glucanases. The elution profile detected at $280 \mathrm{~nm}$ is shown. After application of the sample the column was washed with three volumes. A $\mathrm{NaCl}-$ gradient was then applied. Selected fractions were analysed by native PAGE and activity-staining after incubation with laminarin.

sulphite after SDS-PAGE led to a distinct signal (Fig. 6), indicating glycosylation of the enzyme. The preparation of the sample by heating in Laemmli buffer and the following electrophoresis ensured that only covalentlybound glycosyl residues were stained (Beely, 1987). Glu II cleaved cinerean and laminarin; no activity was detectable with carboxymethylcellulose. With amylose,
Table 1. Purification of the cinerean-cleaving 1,3- $\beta$ glucanase Glu II from the culture supernatant of B. cinerea

Yields and purification factors were not calculated because in steps 1-4 Glu II was not the only activity determined.

\begin{tabular}{lccc}
\hline \hline \multirow{2}{*}{ Step } & $\begin{array}{c}\text { Total } \\
\text { protein }(\mathrm{mg})\end{array}$ & $(\mathrm{U})$ & $\left(\mathrm{U} \mathrm{mg}^{-1}\right)$ \\
\cline { 3 - 4 } \multicolumn{1}{c}{ Cunereanase activity } \\
Lyophilization & 162 & $56 \cdot 7$ & $0 \cdot 35$ \\
Sephacryl-200 & 104 & $39 \cdot 5$ & $0 \cdot 38$ \\
CM-Biogel & 34 & $29 \cdot 6$ & 0.87 \\
Sephadex G-100 & 7 & $12 \cdot 5$ & $1 \cdot 78$ \\
& 2 & $5 \cdot 4$ & $2 \cdot 72$ \\
\hline \hline
\end{tabular}
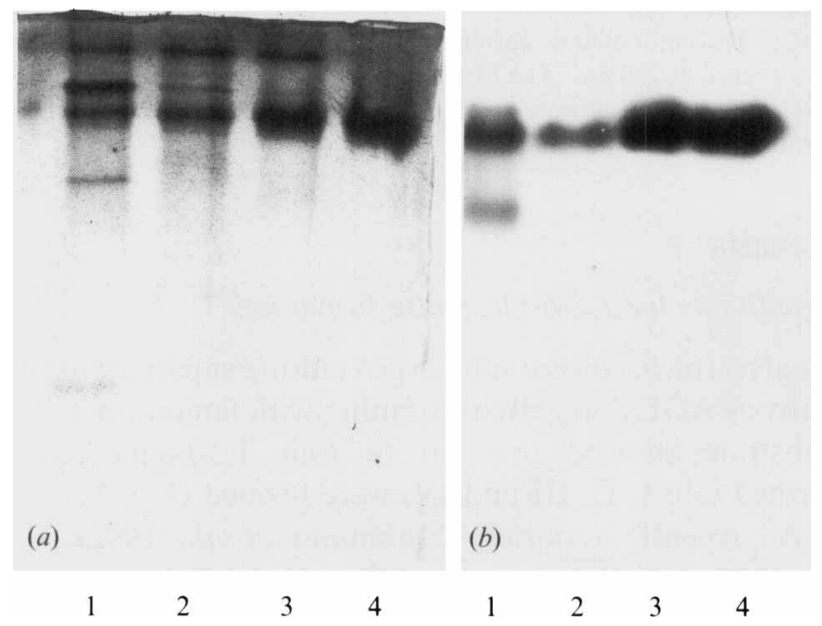

Fig. 4. Identification of the isolated 1,3- $\beta$-glucanase as Glu II. Native PAGE $(17.5 \%)$ of the purification steps. (a) Silver-staining; $(b)$ activitystaining after incubation with laminarin. Lanes: 1, culture supernatant; 2, S-200 pool; 3, CM-Biogel pool; 4, G-100 pool.

amylopectin, glycogen and pustulan, less than $1 \%$ of the activity determined with cinerean was found. Laminaribiose and $p$-nitrophenyl $\beta$-D-glucopyranoside were not degraded. The cleavage products were identified by HPTLC as well as by anion-exchange chromatography of their borate complexes. Cinerean was cleaved to glucose and gentiobiose. Gentiobiose was not degraded. The only degradation product of laminarin was glucose. Neither the degradation of cinerean, nor that of laminarin, liberated oligomers. Furthermore, the linear decrease of viscosity and the simultaneous linear increase of reducing groups during the degradation of cinerean (Fig. 7) indicated that Glu II acted as an exo-1,3- $\beta$ glucanase (EC 3.2.1.58), cleaving one 1,3- $\beta$-linkage after the other, bypassing 1,6- $\beta$-branches. As determined by viscometry, the presence of glucose $(40 \mathrm{~mm})$ and gentiobiose $(10 \mathrm{mM})$ during cinerean degradation had no inhibitory effect. The study of reaction rates as a function of substrate concentration fitted Michaelis-Menten kin- 


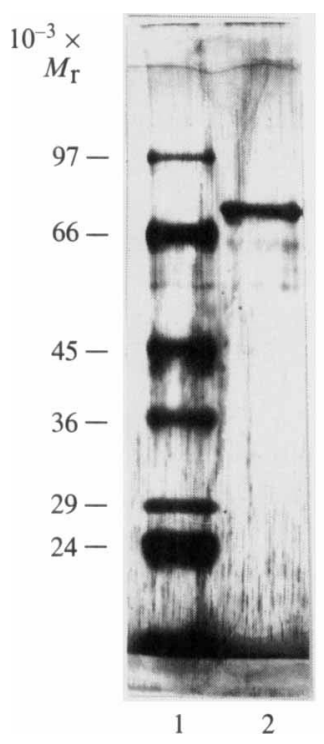

Fig. 5

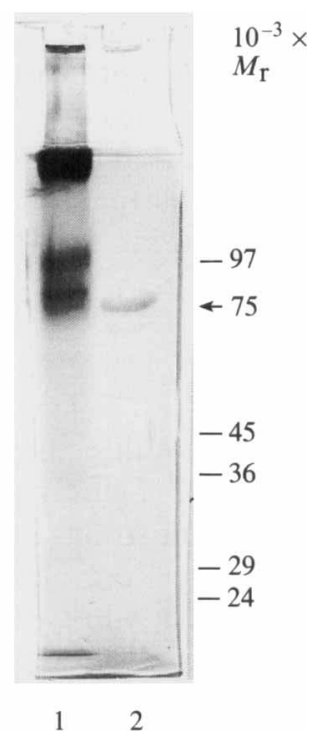

Fig. 6
Fig. 5. Determination of the $M_{\mathrm{r}}$ of Glu II by SDS-PAGE. The gel $(12.5 \%)$ was stained with silver; $10 \mu \mathrm{g}$ Glu II was applied. Lanes: 1 , standards [phosphorylase $b$ (97300), BSA (66000), egg albumin (45000), glyceraldehyde-3-phosphate dehydrogenase (36000), carbonic anhydrase (29000), trypsinogen (24000)]; 2, G-100 pool. $M_{\mathrm{r}}$ of Glu II was calculated after linear regression of $\log M_{\mathrm{r}}$ and $R_{F}$.

Fig. 6. Staining of Glu II glycosyl moieties. SDS-polyacrylamide gel $(12.5 \%)$ stained with Schiff's reagent. Lanes: 1 , culture supernatant; 2 , isolated Glu II.

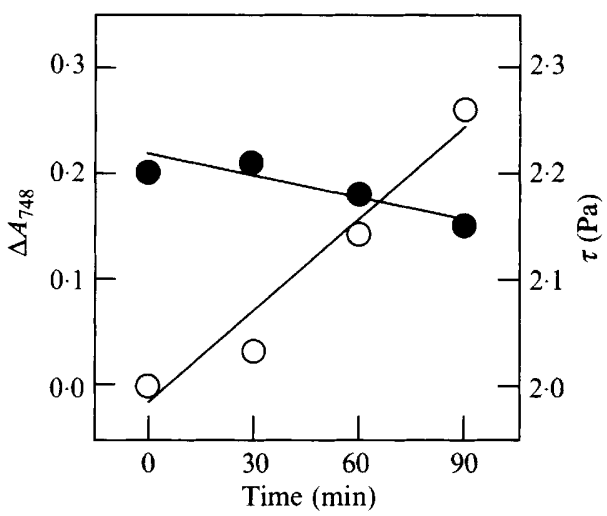

Fig. 7. Time course of reducing group liberation and viscosity decrease. Cinerean $\left(2 \mathrm{mg} \mathrm{ml}^{-1}\right)$ was digested by $1.4 \mathrm{nU} \mathrm{ml}^{-1}$ Glu II at $37^{\circ} \mathrm{C}$ and pH 5.0. After 30,60 and $90 \mathrm{~min}$ the increase of reducing groups $(\mathrm{O})$ was detected colorimetrically. Additionally flow curves were measured and the shear stress, $\tau(\boldsymbol{O})$ was calculated at a rate of $225 \mathrm{~s}^{-1}$.

etics. A concentration of $580 \mu \mathrm{g}$ cinerean $\mathrm{ml}^{-1}\left(\mathrm{~S}_{0.5}\right)$ was calculated for half-maximal velocity. For laminarin $\mathrm{S}_{0.5}$ was $152 \mu \mathrm{g} \mathrm{ml}^{-1}$. When cinerean was used as the substrate, polymer hydrolysis was $\mathrm{pH}$-dependent, showing a maximum at $\mathrm{pH} 3.5$. Laminarin cleavage was less $\mathrm{pH}$ sensitive: at $\mathrm{pH} 6$, for example, Glu II reached $85 \%$ of its maximal activity with laminarin but only $65 \%$ with cinerean. Temperature stability of the enzyme was

\section{Table 2. Purification of the 1,3- $\beta$-glucanase Glu III}

Yields and purification factors were not calculated because in steps $1-4$ Glu III was not the only activity determined.

\begin{tabular}{lccc}
\hline \hline & & \multicolumn{2}{c}{ Laminarinase activity } \\
\cline { 3 - 4 } \multicolumn{1}{c}{ Step } & $(\mathrm{mg})$ & $(\mathrm{U})$ & $\left(\mathrm{U} \mathrm{mg}^{-1}\right)$ \\
\hline Culture supernatant & 162 & 284 & $1 \cdot 7$ \\
Lyophilization & 164 & 211 & $2 \cdot 0$ \\
Sephacryl-200 & 31 & $96 \cdot 1$ & $3 \cdot 1$ \\
CM-Biogel & $1 \cdot 5$ & $13 \cdot 6$ & $9 \cdot 1$ \\
DEAE-Sephadex & $0 \cdot 5$ & $9 \cdot 2$ & $18 \cdot 4$ \\
Sephadex G-100 & $0 \cdot 3$ & $7 \cdot 1$ & $23 \cdot 7$ \\
\hline
\end{tabular}

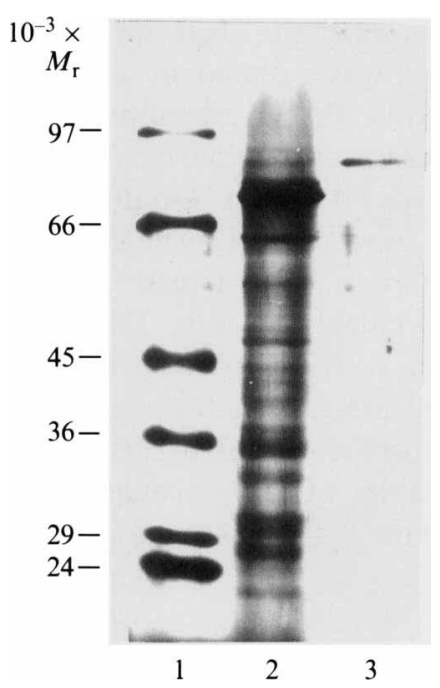

Fig. 8. Determination of the $M_{\mathrm{r}}$ of Glu III by SDS-PAGE. The gel $(12.5 \%)$ was stained with silver; $5 \mu \mathrm{g}$ Glu III was applied. Lanes: 1 , standards [phosphorylase $b$ (97300), BSA (66000), egg albumin (45000), glyceraldehyde-3-phosphate dehydrogenase (36000), carbonic anhydrase (29000), trypsinogen (24000)]; 2, culture supernatant; 3, G100 pool. The $M_{\mathrm{r}}$ of Glu III was calculated after linear regression of $\log$ $M_{\mathrm{r}}$ and $R_{F}$.

determined with $50 \mathrm{~mm}$-sodium acetate buffer $\mathrm{pH} 5.0$. Incubation at $60^{\circ} \mathrm{C}$ for $10 \mathrm{~min}$, and at $70^{\circ} \mathrm{C}$ for $5 \mathrm{~min}$, led to $99 \%$ inactivation. After incubation at $37^{\circ} \mathrm{C}$ for $24 \mathrm{~h}$ and at $4{ }^{\circ} \mathrm{C}$ for one year, no decrease in Glu II activity was detectable.

\section{Purification and properties of Glu III}

During growth of $B$. cinerea on glucose as the carbon source, no cinereanase activity was detectable by the Nelson test, although Glu III was found in the culture supernatant by activity-stained native PAGE. This laminarinase activity was also purified to homogeneity in SDS-PAGE to compare its properties with Glu II (Table 2). The $M_{\mathrm{r}}$ was found to be 84000 (Fig. 8). No cinerean degradation was detectable by the Nelson test, vis- 
cometry, HPTLC or anion-exchange chromatography. However, laminarin was hydrolysed to glucose; no laminaribiose or oligomers were detected. Therefore Glu III, like Glu II, was regarded as an exo-1,3- $\beta$-glucanase (EC 3 2.1.58), but differing in its inability to bypass 1,6$\beta$-branches. Its affinity to laminarin $\left(S_{0.5} 119 \mu \mathrm{g} \mathrm{ml}^{-1}\right)$ was similar to that of Glu II.

\section{Properties of Glu I and Glu IV}

Urbanek \& Zalewska-Sobczak (1986) described an endo1,3- $\beta$-glucanase from the culture supernatant of $B$. cinerea. As Glu II and Glu III proved to be exo-cleaving enzymes, the remaining glucanases, Glu I and Glu IV, were studied to elucidate their specificity and mode of cleavage. Glu I was isolated by electroelution from a preparative native PAGE of culture supernatant after growing $B$. cinerea on laminarin. A preparation homogeneous in native PAGE was obtained (Fig. 1). Cinerean and laminarin were both cleaved in an exo-manner. An $\mathrm{S}_{0.5}$ of $275 \mu \mathrm{g} \mathrm{ml}^{-1}$ for cinerean and $138 \mu \mathrm{g} \mathrm{m}^{-1}$ for laminarin was calculated. Glu IV was obtained from cultures grown with gentiobiose as the single carbon source. The culture supernatant contained only Glu IV and was therefore not treated further. Glu IV had the smallest $\mathbf{S}_{0.5}$ values of the glucanases compared in this work: $171 \mu \mathrm{g} \mathrm{ml}^{-1}$ for cinerean and $27 \mu \mathrm{g} \mathrm{ml}^{-1}$ for laminarin.

\section{Endoglycosidase $H$ and $N$-glycosidase $F$ treatment}

Multiple forms of Saccharomyces cerevisiae invertase (Trimble \& Maley, 1977) and Penicillium camembertii lipase (Isobe \& Nokihara, 1991) due to postsecretional partial deglycosylation were transformed to homogeneous deglycosylated proteins by endoglycosidase $\mathrm{H}$ in vitro. The glycosylation of Glu II has been shown above. The removal of the covalently-bound residues by endoglycosidase $\mathrm{H}$ and $\mathrm{N}$-glycosidase $\mathrm{F}$ was studied. Neither had any effect on the purified enzymes or on a culture supernatant containing all four $1,3-\beta$-glucanases. In all cases, the electrophoretic mobilities of treated and untreated glucanases in native and SDS-PAGEs were the same. The reactivity of Glu II with Schiff's reagent was also unchanged.

\section{Protease treatment}

Movahedi \& Heale (1990) purified and characterized a proteinase secreted by $B$. cinerea. About $0.2 \mathrm{U} \mathrm{ml}^{-1}$ of this enzyme activity, recognizable by its pepstatin sensitivity, was found in the cinereanase-containing culture supernatant. Because Nagata et al. $(1990 a, b)$ found a proteolytic digestion of Flavobacterium dormin- ator 1,3- $\beta$-glucanase II to 1,3- $\beta$-glucanase I, experiments with $B$. cinerea protease, proteinase $\mathrm{K}$ and protease type XIII were carried out. The enriched glucanases were not affected, nor did a concentrated culture supernatant containing all four enzymes change its 1,3- $\beta$-glucanases composition, as shown by native PAGE and activitystaining.

\section{Discussion}

The results of this study show that $B$. cinerea forms four different $1,3-\beta$-glucanases. From the identical enzyme pattern of the strains Lu $1458 \mathrm{MaB}$, SAS 405 and SAS 56 we conclude a prevalent presence of this enzyme system in $B$. cinerea wild-types. All four enzymes acted in an exo-manner. The endo-1,3- $\beta$-glucanase described by Urbanek \& Zalewska-Sobczak (1986) was not detected in our strains. They were working with a strain isolated from an apple, and found that the endo-enzyme was present especially on infected apple. This particular form may therefore be formed under special induction conditions or it may be a special feature of this isolate. An endo-enzyme would have been the key to a sequential induction mechanism as described for the pectic enzymes of $B$. cinerea (Leone \& Van Den Heuvel, 1986). In that case, a constitutive polygalacturonase liberated galacturonic acid, which triggered a number of polygalacturonase and pectinesterase isoenzymes. The lack of an endo-1,3- $\beta$-glucanase in LU $1458 \mathrm{MaB}$, as well as the absence of oligomers during cinerean degradation in vitro, argues against $1,3-\beta$-glucose oligomers as inducer molecules. As LU $1458 \mathrm{MaB}$ clearly recognized cinerean (Stahmann et al., 1992), the mechanism perhaps works with the undegraded macromolecule. Gentiobiose seems unlikely to function as an inducer because when used as carbon source, it had little effect on cinereanase formation, and growth on laminarin as the sole carbon source led to the same specific cinereanase activity as cinerean itself (Stahmann et al., 1992).

Glu II was studied in detail because it was the dominant cinereanase during the polymer degradation phase after growth on glucose. Its $M_{\mathrm{r}}$ of 75000 is equal to that of a Mucor hiemalis exo-1,3- $\beta$-glucanase, and very similar to that of a Rhizoctonia solani enzyme (74000), both characterized by Ohno et al. $(1986,1989)$. The glycosylation of $1,3-\beta$-glucanases as shown for Glu II is a property described for Penicillium oxalicum (CopaPatino et al., 1989), Sclerotium glucanicum (Rapp, 1989), and several yeasts (Nombela et al., 1988; Villa et al., 1978). Glu II cleaved cinerean and laminarin in the same way as 1,3- $\beta$-glucanases from Trichoderma harzianum (Dubourdieu et al., 1985) and Basidiomycete strain QM 806 (Nelson et al., 1969). Because of its inability to cleave gentiobiose Glu II can be used as a tool for the 
Table 3. Properties of Botrytis cinerea 1,3- $\beta$-glucanases

\begin{tabular}{lccccc}
\hline \hline & & & \multicolumn{2}{c}{$\mathrm{S}_{0.5}\left(\mu \mathrm{g} \mathrm{ml}^{-1}\right)$} & \\
\cline { 4 - 6 } Glucanase & $\mathrm{pI}$ & $M_{\mathrm{r}}$ & Cinerean & Laminarin & $\begin{array}{c}\text { Mode of } \\
\text { cleavage }\end{array}$ \\
\hline Glu I & $4 \cdot 9$ & - & $275 \pm 38$ & $138 \pm 21$ & exo \\
Glu II & $5 \cdot 2$ & 75000 & $580 \pm 51$ & $152 \pm 33$ & exo \\
Glu III & $3 \cdot 6$ & 84000 & NAD & $119 \pm 22$ & exo \\
Glu IV & $3 \cdot 4$ & - & $171 \pm 29$ & $27 \pm 3$ & exo \\
\hline \hline
\end{tabular}

NAD, No activity detectable.

determination of the degree of branching of $1,3-\beta$ glucans. Interestingly, Glu III was unable to cleave cinerean. This was also found by Dubourdieu \& Ribereau-Gayon (1980). They studied $B$. cinerea to find a cinereanase and found a laminarin-degrading activity unable to hydrolyse the cinerean which often appears during wine making. Copa-Patino et al. (1989) purified a 1,3- $\beta$-glucanase of Penicillium oxalicum, which also cleaved laminarin but no cinerean. They presumed an inhibition of the enzyme by melanin, which is associated with cinerean (Bull, 1970). In the case of Glu III this reason was ruled out by a direct comparison with Glu II using the same substrate charge. The ability of Glu II to digest cinerean was more sensitive to a $\mathrm{pH}$ change than the cleavage of laminarin. Obviously a conformational change in the enzyme caused reduced accessibility to the $1,3-\beta$-linkages sterically hindered by the $1,6-\beta$ - glycosyl residues. An uptake of the 1,6- $\beta$-glycosyl residues into the active site could be excluded because neither glucose nor gentiobiose showed an inhibition effect. Noncompetitive inhibition of Sclerotium glucanicum 1,3- $\beta$ glucanase activity by glucose was found by Rapp (1989). The differences between Glu I and Glu IV were not as great but were still significant (Table 3). The $S_{0.5}$ of Glu IV for laminarin was one order of magnitude lower than most reported values (Schomburg \& Salzmann, 1986). If the $M_{\mathrm{r}}$ values of the substrates used are assumed to be 912000 for cinerean (Dubourdieu \& Ribereau-Gayon, 1981 ) and 5000 for laminarin (Burchard, 1985), a $K_{\mathrm{m}}$ of $0.3 \mu \mathrm{M}$ for cinerean and of $28 \mu \mathrm{M}$ for laminarin can be calculated for Glu IV. Only this calculation makes it clear that the enzyme has a greater affinity for cinerean than for laminarin.

The significance of $B$. cinerea 1,3- $\beta$-glucanases as catabolic tools is an obvious conclusion of our work. They are extracellular and their formation is influenced by environmental substances (Stahmann et al., 1992). Three of them can be used by the fungus for the degradation of the reserve polysaccharide cinerean. The heterogeneity of these enzymes may be useful for the survival of $B$. cinerea as a relatively unspecific parasitic and saprophytic fungus. We support the isoenzyme concept as a reason for this heterogeneity. Multiple enzyme forms could be the result of evolution from simple enzymic patterns in response to changing hosts or habit (Willetts et al., 1977). However, although differences in specificity and affinity are probably not due to a difference in glycosylation as shown for invertase (Lampen, 1971), and proteolytic processing was not observed as for a Trichoderma viride endo-1,4- $\beta$ glucanase (Stahlberg et al., 1988), certainty will only be achieved by a sequence analysis of the peptides or genes.

These studies were supported by the Bundesministerium für Forschung und Technologie and BASF. K.P.S. is a fellow of the Studienstiftung des deutschen Volkes. We thank F. Faretra (Bari, Italy) for contributing his single-ascospore isolates.

\section{References}

BAMFORTH, C. W. (1980). The adaptability, purification and properties of exo- $\beta 1,3$-glucanase from the fungus Trichoderma reesei. Biochemical Journal 191, 863-866.

BARTNICKI-GARCIA, S. (1968). Cell wall chemistry, morphogenesis, and taxonomy of fungi. Annual Review of Microbiology 22, 87-105.

BARTNICKI-GARCIA, S. (1987). The cell wall: a crucial structure of fungal evolution. British Mycological Society Symposium 13, $389-403$.

BEELY, J. G. (1987). Glycoprotein and Proteoglycan Techniques. Amsterdam, New York \& Oxford: Elsevier.

BodenmanN, J., Heiniger, U. \& HoHL, H. R. (1984). Extracellular enzymes of Phytophthora infestans: endo-cellulase, $\beta$-glucosidase, and 1,3- $\beta$-glucanases. Canadian Journal of Microbiology 31, 75-82.

BuLL, A. T. (1970). Inhibition of polysaccharases by melanin: enzyme inhibition in relation to mycolysis. Archives of Biochemistry and Biophysics 137, 345-356.

BuRCHARD, W. (1985). Polysaccharide. Berlin, Heidelberg, New York \& Tokyo: Springer.

Copa-Patino, J. L., Reyes, F. \& Perez-Leblic, M. I. (1989). Purification and properties of a 1,3- $\beta$-glucanase from Penicillium oxalicum autolysates. FEMS Microbiology Letters 65, 285-292.

Dubourdieu, D. \& Ribereau-Gayon, P. (1980). Mise en evidence d'une $\beta$-(1-3)-glucanase exocellulaire chez Botrytis cinerea. Comptes Rendus de l'Academie des Sciences Paris 290, 25-28.

Dubourdieu, D. \& Ribereau-Gayon, P. (1981). Structure of the extracellular $\beta$-D-glucan from Botrytis cinerea. Carbohydrate $R e-$ search 93, 294-299.

Dubourdieu, D., Desplanques, C., Villetaz, J. C. \& RibereauGAYON, P. (1985). Investigations of an industrial $\beta$-D-glucanase from Trichoderma harzianum. Carbohydrate Research 144, 277-287.

Faretra, F., Antonnacci, E. \& Pollastro, S. (1988). Sexual behaviour and mating system of Botryotinia fuckeliana, teleomorph of Botrytis cinerea. Journal of General Microbiology 134, 2543-2550.

IsOBE, K. \& Nokinara, K. (1991). Physicochemical properties of mono- and diacylglycerol lipase from Penicillium camembertii. In Lipases: Structure, Mechanism and Genetic Engineering (GBF Monograph 16), pp. 345-348. Edited by L. Alberghina, R. D. Schmid \& R. Verger. Weinheim: VCH.

Jones, D., Gordon, A. H. \& BaCon, J. S. D. (1973). Co-operative action by endo- and exo- $\beta$ - $(1-3)$ glucanases from parasitic fungi in the degradation of cell wall glucans of Sclerotinia sclerotiorum (Lib.) de Bary. Biochemical Journal 140, 47-55.

Kitamoto, Y., Kono, R., Shimotori, A., Mori, N. \& Ichikawa, Y. (1987). Purification and properties of exo- $\beta$-1,3-glucanase from Trichoderma harzianum. Agricultural and Biological Chemistry 51, 3385-3386.

LAEMMLI, U. K. (1970). Cleavage of structural proteins during the assembly of the head of bacteriophage T4. Nature, London 227, 680-685. 
LAMPEN, J. O. (1971). Yeast and Neurospora invertases. In The Enzymes, vol. 5, pp. 291-305. Edited by P. D. Boyer. New York \& London: Academic Press.

LEONE, G. \& VAN DEN HeUVEL, J. (1986). Regulation by carbohydrates of the sequential in vitro production of pectic enzymes by Botrytis cinerea. Canadian Journal of Botany 65, 2133-2141.

Markwell, M. A. K., HaAs, S. M., Bieber, L. L. \& Tolbert, N. E. (1978). A modification of the Lowry procedure to simplify protein determination in membrane and lipoprotein samples. Analytical Biochemistry 87, 206-210.

Meril, C. R., Goldmann, D., Sedmann, S. A. \& Ebert, M. H. (1981). Ultrasensitive stain for proteins in polyacrylamide gels shows regional variation in cerebrospinal fluid proteins. Science 211, 1437-1438.

Montant, P. C. \& Thomas, L. (1977). Structure d'un glucane exocellulaire produit par le Botrytis cinerea (Pers.). Annales des Sciences Naturelles Botanique et Biologie Végétale 18, 185-192.

Montant, P. C. \& Thomas, L. (1978). Proprietes physico-chimiques du $\beta(1,3) \beta(1,6)$ glucane exocellulaire produit par le Botrytis cinerea (Pers.). Annales des Sciences Naturelles Botanique et Biologie Végétale 19, 39-43.

MovaHedi, S. \& Heale, J. B. (1990). Purification and characterization of an aspartic proteinase secreted by Botrytis cinerea Pers ex Pers in culture and in infected carrots. Physiological and Molecular Plant Pathology 36, 289-302.

Nagata, S., SaWatani, M., Kuriyama, M., Misono, H. \& Nagasaki, S. $(1990 a)$. Purification and characterization of nonlytic endo- $\beta-1,3-$ glucanase I from Flavobacterium dorminator var. glucanolyticae. Agricultural and Biological Chemistry 54, 2107-2114.

Nagata, S., Maru, I., Ishihara, F., Misono, H. \& Nagasaki, S. $(1990 b)$. Cloning and expression of endo- $\beta$-1,3-glucanase gene from Flavobacterium dorminator in Escherichia coli and characterization of the gene product. Agricultural and Biological Chemistry 54, 2675-2680.

NeLson, N. (1944). A photometric adaptation of the Somogyi method for the determination of glucose. Journal of Biological Chemistry 153, $375-380$.

Nelson, T. E., Johnson, J., Jantzen, E. \& Kirkwood, S. (1969). Action pattern and specificity of an exo- $\beta$-(1-3)-D-glucanase from Basidiomycetes species QM 806. Journal of Biological Chemistry 244, 5972-5980.

Nombela, C., Molina, M., Cenamor, R. \& Sanchez, M. (1988). Yeast $\beta$-glucanases: a complex system of secreted enzymes. Microbiological Sciences 5, 328-332.

Ohno, N., Hashimoto, Y. \& Yadomae, T. (1986). Purification and properties of an exo-(1-3)- $\beta$-D-glucanase from the culture filtrate of Mucor hiemalis. Carbohydrate Research 158, 217-226.

Ohno, N., Nono, I. \& Yadomae, T. (1989). Enzymatic and physiological properties of an exo-(1-3)- $\beta$-D-glucanase from Rhizoctonia solani. Carbohydrate Research 194, 261-271.

PAN, S.-Q., YE, X. S. \& KUC, J. (1989). Direct detection of $\beta-1,3-$ glucanase isozymes on polyacrylamide electrophoresis and isoelectrofocusing gels. Analytical Biochemistry 182, 136-140.
Pielken, P., Stahmann, P. \& Sahm, H. (1990). Increase in glucan formation by Botrytis cinerea and analysis of the adherent glucan. Applied Microbiology and Biotechnology 33, 1-6.

RAPP, P. (1989). 1,3- $\beta$-glucanase, 1,6- $\beta$-glucanase and $\beta$-glucosidase activities of Sclerotium glucanicum: synthesis and properties. Journal of General Microbiology 135, 2847-2858.

Robertson, E. F., Dannelly, H. K., Malloy, P. J. \& Reeves, H. C. (1987). Rapid isoelectric focusing in a vertical polyacrylamide minigel system. Analytical Biochemistry 167, 290-294.

Sancez, M., Nombela, C., Villanueva, J. R. \& Santos, T. (1982). Purification and partial characterization of a developmentally regulated 1,3- $\beta$-glucanase from Penicillium italicum. Journal of General Microbiology 128, 2047-2053.

SchimZ, K.-L., IrRGANG, K. \& OverhofF, B. (1985). Trehalose, a cytoplasmatic disaccharide of Cellulomonas sp. DSM 20108: its identification, carbon-source dependent accumulation, and degradation during starvation. FEMS Microbiology Letters 30, 165-169.

Schomburg, D. \& SAlzManN, M. (1986). Enzyme Handbook 4. Berlin, Heidelberg, New York \& Tokyo: Springer.

SOMOGY, M. (1952). Notes of sugar determination. Journal of Biological Chemistry 195, 19-23.

Stahlberg, J., Johansson, G. \& Pettersson, G. (1988). A bindingsite-deficient, catalytically active, core protein of endo-glucanase III from the culture filtrate of Trichoderma reesei. European Journal of Biochemistry 173, 179-183.

Stahmann, K.-P., Pielken, P., Schimz, K.-L. \& Sahm, H. (1992). Degradation of extracellular $\beta-(1,3)(1,6)$-D-glucan by Botrytis cinerea. Applied and Environmental Microbiology 58, 3347-3354.

TANGerone, B., Royer, J. C. \& NaKas, J. P. (1989). Purification and characterization of an endo- $\beta-1,3$ glucanase from Trichoderma longibrachiatum. Applied and Environmental Microbiology 55, 177-184.

Trimble, R. B. \& Maley, F. (1977). Subunit structure of external invertase from Saccharomyces cerevisiae. Journal of Biological Chemistry 252, 4409-4412.

URBANEK, H. \& ZALEWSKA-SOBCZAK, J. (1986). 1,4- $\beta$-Galactanases and $1,3-\beta$-glucanases of Botrytis cinerea isolate infecting apple. Biochemie und Physiologie der Pflanzen 181, 321-329.

Usui, T., TotanI, K., TotsuKa, A. \& OGUCHI, M. (1985). Purification of endo-(1-3)- $\beta$-D-glucanases lysing yeast cell walls from Rhizoctonia solani. Biochimica et Biophysica Acta 840, 255-263.

Villa, T. G., Notario, V. \& VillanueVa, J. R. (1978). Direct chemical proof of different glycosylation pattern for yeast exo- and endo-1,3$\beta$-D-glucanases. Journal of General Microbiology 109, 371-374.

WESSELS, J. G. H. (1988). A steady state model for apical wall growth in fungi. Acta Botanica Neerlandica 37, 3-16.

Willetts, H. J., Byrde, R. J. W., Fielding, A. H. \& Wong, A. L. (1977). The taxonomy of the brown rot fungi (Monilinia spp.) related to their extracellular cell wall-degrading enzymes. Journal of General Microbiology 103, 77-83.

ZaCharius, M. R., Zell, T. E., Morrison, J. H. \& WoOdLock, J. J. (1969). Glycoprotein staining following electrophoresis on acrylamide gels. Analytical Biochemistry 30, 148-152. 